\title{
Effects of oxygen availability on the combustion behaviour of materials in a controlled atmosphere cone calorimeter
}

\author{
DAMIEN M. MARQUIS, ERIC GUILLAUME and ANYCEE CAMILLO \\ Laboratoire national de métrologie et d'essais (National laboratory for testing and metrology) \\ 29 Avenue Roger Hennequin, 78197 TRAPPES Cedex - FRANCE
}

\begin{abstract}
The reaction-to-fire of materials is commonly studied with bench scale experiments conducted under controlled test conditions. Two bench-scale instruments commonly used for this purpose are the cone calorimeter and the fire propagation apparatus. Research performed with these test apparatuses on the burning behaviour of polymeric materials has demonstrated the significant effect on the results of test variables such as pressure, irradiance, flow velocity, etc. In spite of the fairly large number of studies, little is known concerning the effect of oxygen vitiation and reduced ventilation on the burning behaviour of polymeric materials. Recent work in a controlled oxygen environment raises the question of interpretation and accuracy of the results. This paper reports the results of a study to evaluate the effect of oxygen vitiation and reduced ventilation on the burning behaviour of materials in a controlled atmosphere cone calorimeter. The study was performed on a typical thermoplastic material, i.e., a black poly(methyl)methacrylate. The dependence of the results on the experimental fire conditions is presented and discussed. The experiments show that the inlet airflow rate is a major factor to consider when studying the burning behaviour of polymeric materials in an enclosure. It strongly affects the available amount of oxygen that can react and may lead to a misinterpretation of the results when the effects of oxygen are studied.
\end{abstract}

KEYWORDS: controlled atmosphere cone calorimeter, oxygen vitiation, ventilation conditions

\section{NOMENCLATURE LISTING}

$D_{a} \quad$ Damköhler number

$\Delta h \quad$ Net enthalpy $\left(\mathrm{kJ}^{\mathrm{kg}} \mathrm{kg}^{-1}\right)$

$\dot{m}^{\prime \prime} \quad$ Mass flow rate per unit area $\left(\mathrm{kg} . \mathrm{s}^{-1} \mathrm{~m}^{-2}\right)$

$\dot{Q} \quad$ Heat release rate $(\mathrm{kW})$

$\mathrm{T}$ Temperature $(\mathrm{K})$

$\mathrm{t} \quad$ Time (s)

$\dot{v} \quad$ Volume flow rate $\left(\mathrm{m}^{3} \cdot \mathrm{s}^{-1}\right)$

$\mathrm{X}$ Mole fraction $\left(\mathrm{mol} \cdot \mathrm{mol}^{-1}\right)$

Y Mass fraction $\left(\mathrm{kg} \cdot \mathrm{kg}^{-1}\right)$

\section{Greek}

$\beta \quad$ Stoichiometric dilution factor

$\tilde{\gamma}$ Thermal expansion factor

$\phi \quad$ Depletion factor

$\tau_{\text {ch }}$ Chemical time

$\tau_{\mathrm{m}} \quad$ Mixing time

Superscript

A Air

\section{INTRODUCTION}

The fire behaviour of polymer materials is of great interest in fire safety research due to its scientific and practical importance. For more than two decades, the reaction-to-fire of materials has mainly been studied with bench scale experiments to control the test conditions. The most important bench-scale instruments for fire testing are the cone calorimeter (standard and equipped with a controlled atmosphere enclosure) [1-4] and the fire propagation apparatus (FPA) [5], which were developed in the early 1980s. Over the years, these devices have allowed great progress and a better understanding of the physical phenomena occurring when materials burn in well-ventilated conditions. This research has emphasised the significance of factors such as ambient conditions (pressure and humidity) [6-8], flow velocity [8-11], sample orientation [12] and applied irradiance (magnitude and spectral characteristics) [13-15]. In spite of the fairly large number of studies, little attention has been paid to the effects of an atmosphere with reduced oxygen $\left(\mathrm{O}_{2}\right)$. As a result, 
there is a substantial lack of knowledge concerning the effect of reduced ventilation and oxygen vitiation on the condensed phase as well as on gas phase at material scale, but also at larger scale. The production of gaseous products emitted during solid material decomposition depends heavily on parameters such as the local temperature and local oxygen mass fraction. The main references on this topic describe the work of KASHIWAGI et al, [16-18] and TEWARSON et al. $[19,20]$. These authors have studied the reactivity in condensed phase and the combustion in gas phase, respectively. TEWARSON et al explain that the burning behaviour of materials and the species produced vary substantially with the oxygen depletion. If sufficient oxygen is available, combustion is complete. When the amount of oxidizer able to react with the fuel is insufficient, the oxidation reactions lead to the formation of incomplete combustion products such as carbon monoxide $(C O)$, hydrocarbons species, etc. $[19,20]$. Moreover, KASHIWAGI et al. demonstrated that the oxygen concentration also has an impact on the reactivity of condensed media at low irradiance levels. The phenomenon is more significant for porous materials.

In the past few years, renewed interest in the topic of the burning behaviour of materials in under-ventilated conditions motivated studies on the subject using the controlled atmosphere cone calorimeter (CACC) [21]. Recent work raises the question of interpretation and accuracy of the results and draws the attention to the lack of international standardization of the test apparatus and experimental protocol. MARQUIS et al. [21] have recently shown that the design (and volume) of the combustion enclosure may affect the polymer burning behaviour and the accuracy of the measurements. For the CACC with open connection between the combustion enclosure and the exhaust hood of the calorimeter, the authors suggest using a $0.6 \mathrm{~m}$ high chimney to limit the flame blow off by the surrounding laboratory air and reduce post-oxidation. WERREL et al. $[22,23]$ point out that the equations for calculating heat release rate (HRR) should be modified for the CACC with open connection. They developed new equations that account for variations in the flow rate of surrounding air from the laboratory drawn into the calorimeter exhaust hood during a test.

During an experiment in an oxygen-controlled enclosure as in the CACC or the FPA, one of the most significant variables controlling the burning process of materials is the supply rate of oxygen, which is a function of the oxygen concentration and the airflow rate. The supply rate of oxygen entering the enclosure must be carefully selected so that it does not adversely affect the measurement accuracy or lead to misinterpretation of the results. Indeed, using an airflow that is too low may limit the chemical reactions between $\mathrm{O}_{2}$ and gaseous fuel, and lead to errors in estimating the available oxygen in the enclosure. WERREL et al. [23] have shown that oxygen vitiation seems to have a smaller effect than reduced ventilation. Excessive airflow may increase the convective cooling of the sample, but it may also affect the mixing and local concentration of fuel/oxidant in the gas stream. In addition, air velocity may directly affect the reaction rate of the condensed phase. The present paper describes the results of a study of the effects of controlled ventilation conditions on the burning behaviour of materials in an enclosure. The study was performed on a non-charring polymer, i.e., poly(methyl)methacrylate (PMMA). Although its practical use is limited, solid acrylic $P M M A$ polymer has been widely used as a reference material in fire safety engineering [24]. To explore and understand the effects of experimental fire conditions on the reaction to fire of this material, a CACC has been used [21]. The present study complements the work performed on the topic by MARQUIS et al. [21] and WERREL et al. [22,23], and focuses on identifying the differences induced by several CACC designs and test conditions in order to promote standardization.

\section{EXPERIMENTAL SETUP}

\section{Tested materials}

The material used in this study is a non-charring polymer, black poly(methyl)methacrylate, commonly known as Altuglas, supplied by the VACOUR company and synthesized via radical polymerization. The elementary analysis showed that no inert load, flame-retardants or fillers were used during the manufacturing of the PMMA samples; neither chlorine nor sulphur-based additives were found. Based on the results of the analysis, the raw chemical formula of the virgin PMMA was found to be $\left(\mathrm{C}_{4.9} \mathrm{H}_{7.8} \mathrm{O}_{2.0}\right)_{n}$ with $\mathrm{n}$ being the degree of polymerization of PMMA [15]. Samples were conditioned at $(23 \pm 2){ }^{\circ} \mathrm{C}$ and a relative humidity of $(50 \pm 5) \%$ for more than 88 hours, in accordance with the specifications of the ISO 291 standard [25]. The samples were $(100 \pm 2) \mathrm{mm}$ long, $(100 \pm 2) \mathrm{mm}$ wide and $(14 \pm 1) \mathrm{mm}$ thick, with a mass of $(170 \pm 10) \mathrm{g}$. The mass density measured by the pycnometer method [26] was equal to $(1214 \pm 61) \mathrm{kg} \cdot \mathrm{m}^{-3}$. 


\section{Experimental apparatus: Open controlled atmosphere cone calorimeter}

Small-scale experiments were carried out with an "open controlled-atmosphere-cone-calorimeter" (CACC), as named by WERREL et al. [23]. The experimental setup is described in detail in the literature [4,27] and only a brief summary is presented here. The test apparatus [Fig. 1] was developed to study the influence of an oxygen-vitiated environment on thermal degradation and combustion under a range of irradiance levels.

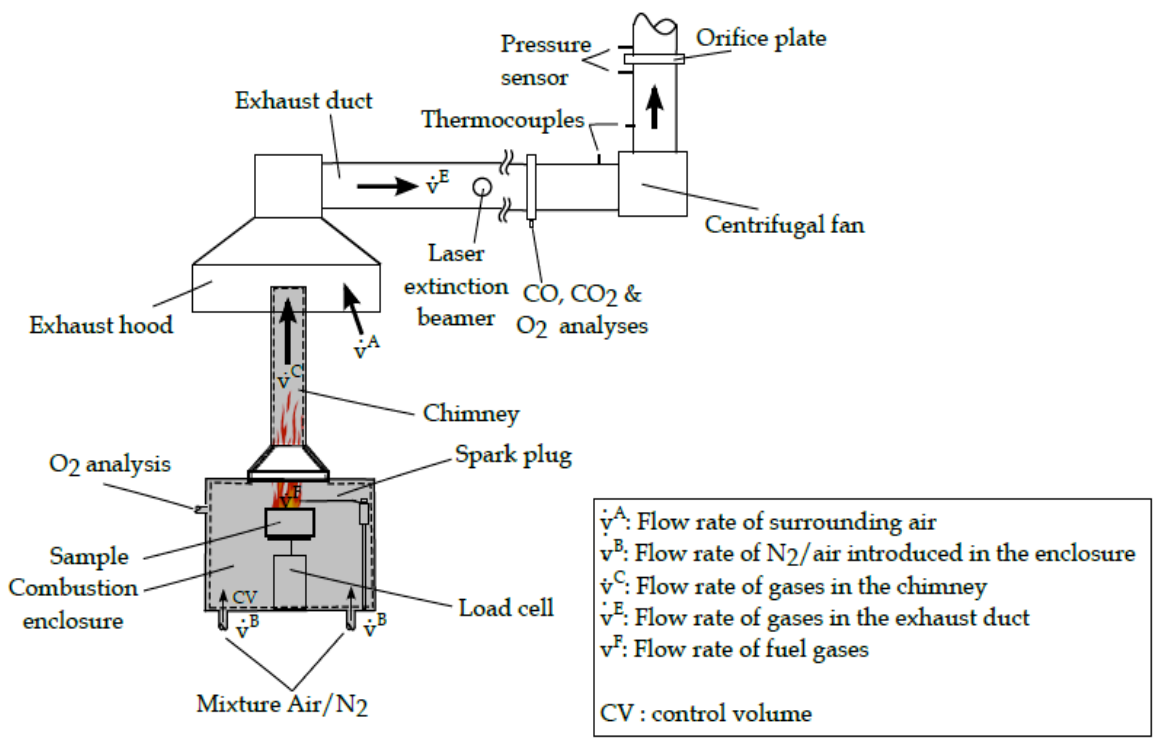

Fig. 1. Controlled atmosphere cone calorimeter apparatus with a chimney above the combustion enclosure

The main difference with the standard cone calorimeter is that the specimen is located inside an enclosure, based on a design developed by MiKKOLA [27]. The enclosure is placed directly underneath the exhaust hood of the standard calorimeter without a direct connection, hence the name open CACC [23]. The enclosure consists of a stainless steel chamber, with the standard truncated cone heater at the top, a door with an observation window in the front and two gas inlet ports at the bottom. To reduce the radiation from the enclosure walls, the top of the combustion enclosure is water-cooled. The two-gas inlet ports at the bottom allow accurate control of the atmosphere inside the enclosure (i.e. the desired gas flow, the desired oxygen and nitrogen concentrations). The inlet atmosphere in the enclosure is adjusted by rotameters to control the volume flow of air and nitrogen, respectively. Mixing is monitored by two oxygen analyzers. One is directly connected to the combustion enclosure and the second in the incoming gas flow. The initial oxygen concentration in the enclosure can be adjusted to any value from $21 \mathrm{vol} \%$ (air) down to 0 vol\%. It can also be used with oxygen concentrations higher than $21 \mathrm{vol} \%$. The test method uses a sample with the same size as that in the standard cone calorimeter, i.e., $100 \times 100 \mathrm{~mm}$. A truncated-cone-shaped heater exposes the sample to a constant irradiance level. A spark plug above the test specimen ignites flammable pyrolyzates. The effluents are collected in the standard exhaust hood of the calorimeter and transported through a duct equipped with a thermocouple, an orifice flowmeter with a pressure sensor, a smoke measurement system and a sampling probe for oxygen $\left(\mathrm{O}_{2}\right)$, carbon monoxide $(\mathrm{CO})$ and carbon dioxide $\left(\mathrm{CO}_{2}\right)$ analyzers.

Because of its open design, the effluents may continue to oxidize with the surrounding air of the laboratory when they emerge from the enclosure, ultimately leading to well ventilated combustion [28]. To reduce this post-oxidation phenomenon outside the test enclosure, a $0.6 \mathrm{~m}$ high chimney is mounted on top of the conical heater. This chimney also prevents backflow of ambient air and ensures the cooling of the gas flow. Several investigators have adopted the HIETANIEMI' approach [28] to limit the post oxidation phenomenon, using different chimney lengths and materials [21-23]. 


\section{Experimental procedure and conditions}

The test procedure is similar to that described in the ISO 5660-1 standard [5] with one major difference, the sample is located in a combustion enclosure. Samples are tested in the horizontal orientation. The sample holder includes a frame that is positioned over the sample. This frame reduces the exposed surface area of the sample $\left(0.008836 \mathrm{~m}^{2}\right)$. Measurements are performed with a $64 \mathrm{~kg} . \mathrm{m}^{-3}$ ceramic fibre insulation pad on the backside of the sample as specified in the ISO 5660-1 standard [5]. During these experiments, the volumetric flow rate of the extraction through the exhaust duct of the calorimeter $\dot{v}^{E}$ is set at $(24 \pm 2) d m^{3} . s^{-}$ ${ }^{1}\left[\right.$ or $(1440 \pm 120){\left.\mathrm{L} . \mathrm{min}^{-1}\right]}$ at $23^{\circ} \mathrm{C}$. Several inlet volume flow rates $\dot{v}^{B}$ were used: $(100 \pm 5) \mathrm{L}_{\mathrm{min}} \mathrm{m}^{-1}$,

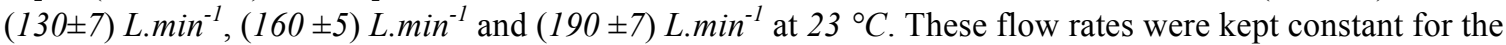
whole duration of each test. Measurements were carried out at $50 \mathrm{~kW} . \mathrm{m}^{-2}$ and at several oxygen concentrations $X_{O_{2}}^{B}(0,5,10,12.5,15$ and $21 \mathrm{vol} \%)$. All tests were carried out three times in order to study the repeatability of the results. Data were collected with a $5 s$ sampling interval. As the test protocol defined in the ISO 5660-1 standard [5] cannot be used for the CACC, a modified test protocol was developed as defined in Ref. [21].

\section{Heat release rate calculation}

Oxygen consumption calorimetry, which is the most common method to measure HRR [29-31], is based on THORNTON's findings [32]. According to this approach, most carbon-based combustibles (gas, liquid or solid) release a constant amount of energy for each unit mass of oxygen consumed, known as "THORNTON'S constant" and equal to $13.1 \mathrm{MJ}_{\mathrm{kg}}{ }^{-1}$ oxygen consumed ( $\pm 5 \%$ for most hydrocarbon fuels) $[33,34]$. For the standard cone calorimeter (according to the ISO 5660-1 standard), the calculation of the HRR is based on JANSSENS' work [30,31]. JANSSENS published a set of equations to calculate the HRR based on oxygen consumption. Based on Hess' Law, he derived a set of equations that address incomplete combustion by considering the generation of carbon monoxide. Unfortunately, the formula proposed by JANSSENS is not valid for the open CACC [22,23]. Due to its open design, the exhaust gases are diluted by excess air drawn from the laboratory environment. The excess air flow rate varies during a test, which affects the baseline oxygen concentration and hence the calculation of the HRR. Recently, WERREL [22,23] showed that the error from ignoring this effect can be as high as $30 \%$ when the oxygen concentration in the enclosure is below $18 \mathrm{vol} \%$. Using JANSSENS's approach [30,31], WERREL defined a modified baseline and developed a new formula [Eq. 1] to calculate the HRR, $\dot{Q}(t)$ (in $k W$ ) in the open CACC. WERREL's equations are given below (see Eqs. 1 \& 2). Details on the derivation of these equations can be found in Refs. [22,23].

$$
\dot{Q}(t)=1.10 \cdot \Delta h_{O_{2}} \cdot X_{o_{2}}^{B} \cdot \dot{m}^{E} \cdot\left[\frac{\phi-0.5\left(\frac{\Delta h_{c o}}{\Delta h_{O_{2}}}-1\right) \cdot(1-\phi) \cdot\left(X_{c o}^{E} / X_{o_{2}}^{E}\right)}{(1-\phi)+\phi\left(1+(\beta-1) X_{O_{2}}^{B}\right)}\right] \cdot\left(1-X_{H_{2} O}^{A} \cdot \widetilde{\gamma}\right)
$$

with the oxygen depletion factor $\phi$ defined by Eq. (2):

$$
\phi(t)=\frac{X_{O_{2}}^{B}\left(1-X_{C 0_{2}}^{E}-X_{C O}^{E}\right)-X_{O_{2}}^{E}\left(1-X_{C 2}^{A} \tilde{\gamma}\right)}{X_{O_{2}}^{B}\left(1-X_{O_{2}}^{E}-X_{C O 2}^{E}-X_{C O}^{E}\right)}
$$

where $\Delta h_{O 2}$ is the net heat of combustion per unit mass of oxygen consumed, assumed to be $12.98 \mathrm{MJ}_{\mathrm{kg}}^{-1} \pm 5 \%$ for $P M M A$, which slightly differs from the average value; $\Delta h_{C O}$ is the net heat release per unit mass of $\mathrm{O}_{2}$ consumed for the oxidation of $\mathrm{CO}$ into $\mathrm{CO}_{2}\left(17.6 .1 \mathrm{MJ}^{\mathrm{kg}} \mathrm{kg}^{-1}\right.$ of $\left.\mathrm{O}_{2}\right) ; \beta$ is the stoichiometric dilution factor $(\beta \approx 1.5[29]) ; \dot{m}^{E}$ is the mass flow rate (in $\mathrm{kg} \cdot \mathrm{s}^{-1}$ ) in the exhaust duct calculated from the pressure drop and the gas temperature at the orifice flow meter according to Ref. [2]; $\tilde{\gamma}$ is a thermal expansion factor; $X_{O_{2}}^{E}, X_{\mathrm{CO}_{2}}^{E}$ and $X_{\mathrm{CO}}^{E}$, are respectively the measured mole fraction of $\mathrm{O}_{2}$, $\mathrm{CO}_{2}$ and $\mathrm{CO}$ in the exhaust duct; $\mathrm{X}_{\mathrm{O}_{2}}^{B}$ is the time dependent intake mole fraction of $\mathrm{O}_{2} ; X_{\mathrm{CO} 2}^{A}$ the measured mole fraction of $\mathrm{CO}_{2}$ in the diluting ambient air and $\mathrm{X}_{\mathrm{H} 2 \mathrm{O}}^{A}$ is the mole fraction of water $\left(\mathrm{H}_{2} \mathrm{O}\right)$ in the diluting ambient air. In the present paper, WERREL's equations are used to calculate the HRR. 


\section{BEHAVIOUR IN NORMAL ATMOSPHERE}

PMMA has been widely studied in fire safety science [6-20]. Research on the burning behaviour of materials has shown that the reaction-to-fire is governed by the ambient environment and by the material's chemical and thermophysical properties. The burning behaviour of PMMA under well-ventilated conditions is described in detail in Refs. [16-20] and will not be discussed in the present article. The reader who desires a complete analysis of a same black PMMA (supplied by VACOUR company) can find detailed information in the work of LUCHE et al. [15].

\section{RESULTS AND DISCUSSIONS}

\section{Effects of reacting atmosphere}

The effect of the reacting atmosphere on the reaction-to-fire of PMMA was studied by modifying the Air $/ \mathrm{N}_{2}$ mixture in the combustion enclosure of the open CACC. The atmosphere in the enclosure was assumed to be identical to that introduced through the inlet. It was kept constant during the test. Triplicate tests were performed at $50 \mathrm{~kW} \cdot \mathrm{m}^{-2}$ and six concentrations of oxygen $X_{o 2}^{B}(0,5,10,12.5,15$ and 21 vol\%). The volume flow of air at the inlet of the combustion enclosure was adjusted to (160 \pm 5$) \mathrm{L}_{\mathrm{min}} \mathrm{m}^{-1}$ at $23{ }^{\circ} \mathrm{C}$.
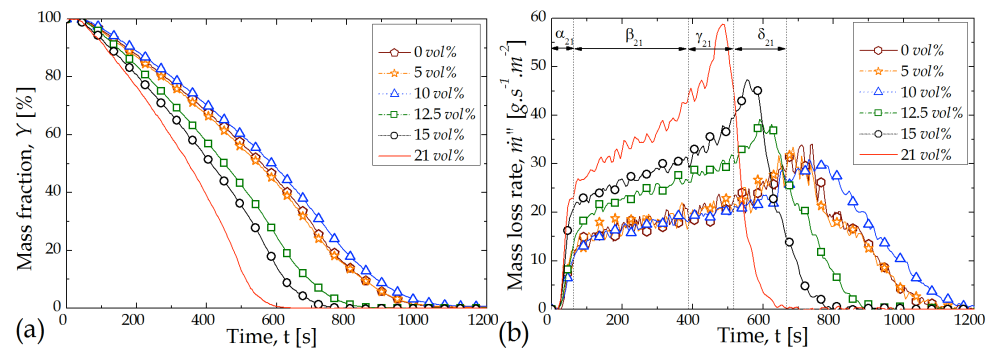

Fig. 2. Effect of the inlet oxygen concentration $X_{o_{2}}^{B}$ on the $P M M A$ behaviour in condensed phase. (a) average mass loss and (b) average MLR.

Fig. 2 illustrates the effects of the reacting atmosphere on the PMMA condensed phase. Each curve represents the average of the three tests. In these graphs, time $t=0 \mathrm{~s}$ corresponds to the beginning of exposure to the radiant heater. The experimental uncertainty (representing both the experimental standard deviation and the measurement uncertainty, with a confidence of $95 \%$ [38]) was estimated to be $\sim 7 \%$, but is not shown in the figures for clarity.

Under normal air (21 vol\% of $\left.O_{2}\right)$, LUCHE et al. [15] found that physical and chemical phenomena taking place during PMMA decomposition consist of 4 steps $\left(\alpha_{21}\right.$ to $\delta_{21}$ as illustrated in Fig. 2 for ambient $\mathrm{O}_{2}$ conditions). The same four steps can be identified for the other curves. Henceforth, each step will be identified for each curve using a subscript reflecting the $\mathrm{O}_{2}$ concentration (e.g., $\alpha_{15}$ for step $\alpha$ at $15 \mathrm{vol} \%$ of $\mathrm{O}_{2}$ ). The steps can be described as follow:

- The first step, $\alpha$, represents the initiation of the chemical reaction and the onset of the nucleation process in depth. Decomposition gases migrate towards the surface because of the induced pressure gradient and buoyancy [16,17], leading to a significant bubbling phenomenon. This is also the period where ignition occurs when the $\mathrm{O}_{2}$ concentration is sufficient to sustain flaming (phenomenon described in the next section).

- The next step, $\beta$, represents the chemical decomposition of the thermally thick sample. The bursting of bubbles leads to the formation of cavities that increase the specific area of the PMMA surface and promote the penetration of oxygen through the melted matrix [16,17], enhancing the oxidation reaction. The rise of pressure of the gaseous products causes swelling. Production of gases and the decomposition rate increase at a slower rate than during the first step.

- The third step, $\gamma$, corresponds to the chemical decomposition of a thermally thin sample. The thermal feedback induced by the ceramic fiber insulation at the back face of the sample enhances the decomposition rate up to an asymptotic value. Swelling also decreases significantly. 
- The final step, $\delta$, characterizes reduction of the mass loss rate (MLR) and the decreased production of decomposition gases. This period also corresponds to flame decay and extinction process regardless of the $\mathrm{O}_{2}$ concentration. At the end, no residue is observed in the sample holder.

Results and experimental observations revealed that the phenomena observed under well-ventilated conditions change at lower $\mathrm{O}_{2}$ concentrations. For example, KASHIWAGI et al. [16,17] found that the physical and chemical processes occurring during the thermal decomposition of PMMA are affected by oxygen depletion. According to these authors, this is due to changes of the intrinsic properties of the matrix - such as the viscosity -, affecting the nucleation process i.e. the frequency, magnitude and the burst of bubbles through the molten matrix. The chemical processes during the PMMA decomposition are discussed in detail in the Refs. [16,17].

At oxygen concentrations of $12.5 \mathrm{vol} \%$ and higher, the decomposition of the solid phase occurs with flaming combustion at the surface of the sample. The MLR is at its highest at $21 \mathrm{vol} \%$ of $\mathrm{O}_{2}$ and lower in a depleted $\mathrm{O}_{2}$ environment as shown in Figs. 2.b \& 3. The latter figure shows the MLR averaged over the decomposition period for all the studied $\mathrm{O}_{2}$ concentrations.

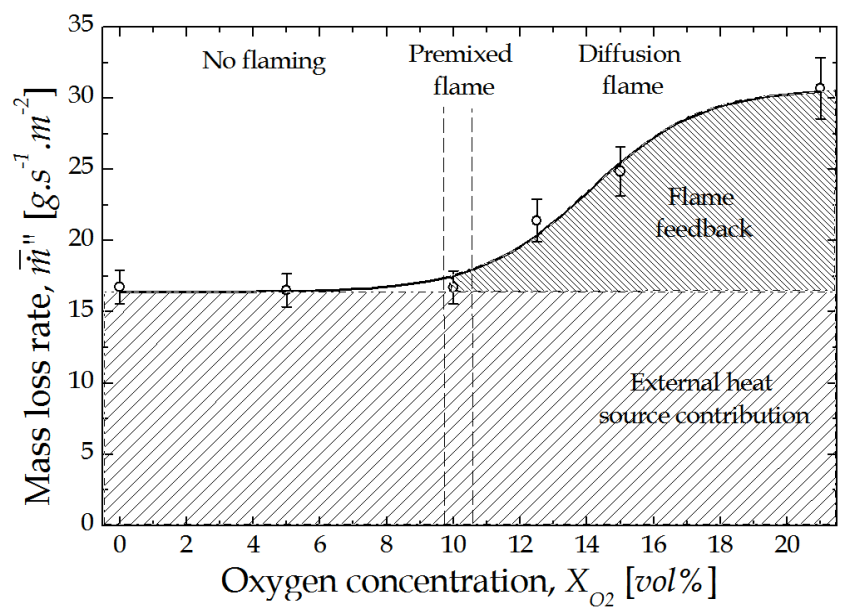

Fig. 3. Average MLR as a function of the inlet oxygen concentration for PMMA.

According to TEWARSON [20], $\mathrm{O}_{2}$ depletion substantially lowers the flame temperature and the combustion efficiency, which, in turn, reduce the radiative feedback received at the $P M M A$ surface and, therefore, the MLR. The lower MLR could also be related to the reduction of oxidation reactions in condensed phase. When a diffusion flame is present at the sample surface (at $12.5 \mathrm{vol} \%$ of $\mathrm{O}_{2}$ or higher), the oxidation reactions of the surface are possible, if it is assumed that oxygen may diffuse through the flame, which is contrary to what many researchers usually assume. According to KASHIWAGI et al. [16,17], once the diffusion flame is established at the surface of the sample, the region above the PMMA surface is deprived of oxygen by the combustion reactions and all oxidative steps at the surface will cease. In addition, as the mass flux of gaseous decomposition products increases over time, the local oxygen concentration above the $P M M A$ surface is reduced by the opposed-flow of fuel gases $\dot{m}_{F}$. Consequently, the possibility of oxidation reactions in the PMMA condensed phase is reduced or eliminated. In presence of a flame, the chemical oxidation reactions in condensed phase seem less important or insignificant for PMMA compared to the thermal processes. The thermal decomposition is therefore mainly controlled by the radiative feedback from the flame and the radiant exitance of the heat source as shown in Fig. 3. When the mass flux of gaseous decomposition products is too low, the flame temperature drops until flame extinction. This phenomenon corresponds to an inflexion point in the mass loss curve (Fig.3.b) and a reduction of the MLR.

For $X_{o_{2}}^{B} \leq 10 \mathrm{vol} \%$, the behaviour in the condensed phase is different because the thermal decomposition processes of the PMMA occur in absence of a diffusion flame at its surface. The MLR is significantly reduced compared to that observed at 21 vol\% of $\mathrm{O}_{2}$. (Figs. 2.b \& 3) In this case, experiments suggest that the effects of $\mathrm{O}_{2}$ concentration of the enclosure atmosphere on the thermal decomposition of the condensed phase seem to be insignificant. Indeed, considering the experimental uncertainties, the graphs of Figs. $2 \&$ 3 indicate that the time-varying mass loss and MLR are identical for oxygen concentrations ranging from 0 to $10 \mathrm{vol} \%$. In absence of a flame, theoretically, the sample surface should be more exposed to oxygen, 
making oxidation of the condensed phase more likely. However, as previously mentioned, after a few seconds of exposure to a $50 \mathrm{~kW} \cdot \mathrm{m}^{-2}$ irradiance level, the gaseous products emission is too intense to allow the diffusion of surrounding oxygen into the degraded $P M M A$, preventing oxidation reactions of the PMMA condensed phase. The nucleation phenomenon resulting from in-depth thermolysis reactions becomes significant compared to the surface oxidation reactions. KASHIWAGI et al. [16,17] have shown for low irradiance levels $\left(17 \mathrm{~kW} . \mathrm{m}^{-2}\right)$, that the oxygen effect at the surface of the condensed phase is more prominent as the mass flux of gaseous products of decomposition $\dot{m}_{F}$ is reduced. From our results, it can be concluded that oxidation reactions at the PMMA surface are possible only when the mass flux of gaseous products of decomposition does not prevent the diffusion of surrounding oxygen. The critical threshold for the mass flow of gaseous products $\dot{m}_{F}^{c}$ beyond which the oxygen diffusion may be neglected depends directly on the net heat flux at the sample surface.

The behaviour of PMMA in the gas phase is presented in Fig. 4. Following Luche et al. [15], all $C$ atoms in the PMMA are converted into $\mathrm{CO}$ and $\mathrm{CO}_{2}$ during the combustion of the material under well-ventilated conditions. The authors did not detect the presence of other compounds containing $\mathrm{C}$ atoms during the decomposition of the materials (except for very small quantities such as heavy hydrocarbons, polycyclic aromatic hydrocarbons, soot, etc.). For this reasons, the analyses were performed only on the aforementioned gaseous species. The graphs reported on this figure illustrate the effects of oxygen concentration in the enclosure on the average HRR and on the average generation rate of gaseous products $\left(\mathrm{CO}\right.$ and $\mathrm{CO}_{2}$ ). Uncertainties were estimated respectively at $12 \%$ for the $\mathrm{HRR}$ and $7 \%$ for the $\mathrm{CO}$ and $\mathrm{CO}_{2}$ production rate.
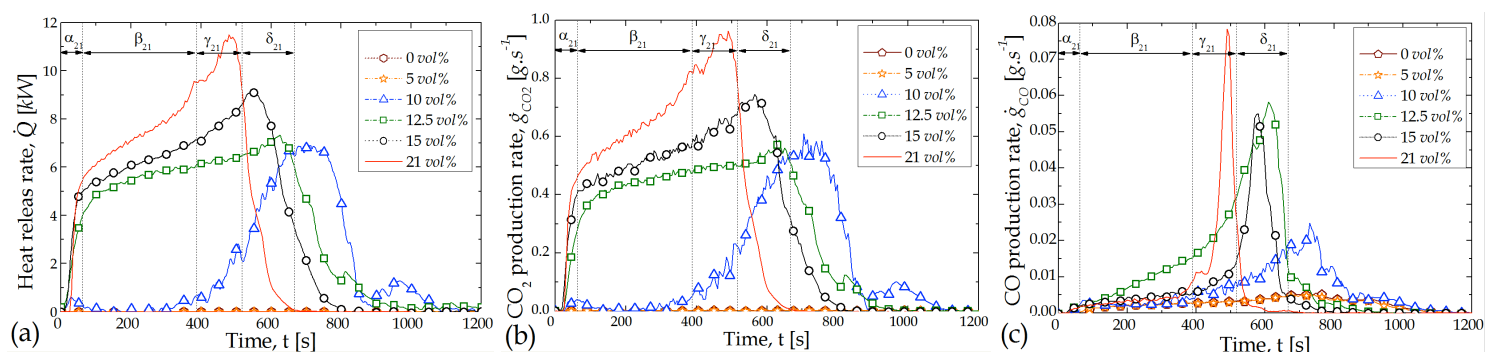

Fig. 4. Effect of oxygen concentration $X_{O_{2}}^{B}$ on the PMMA behaviour in the gas phase. (a) average HRR (b) average generation rate of $\mathrm{CO}_{2}$ and (c) average generation rate of $\mathrm{CO}$.
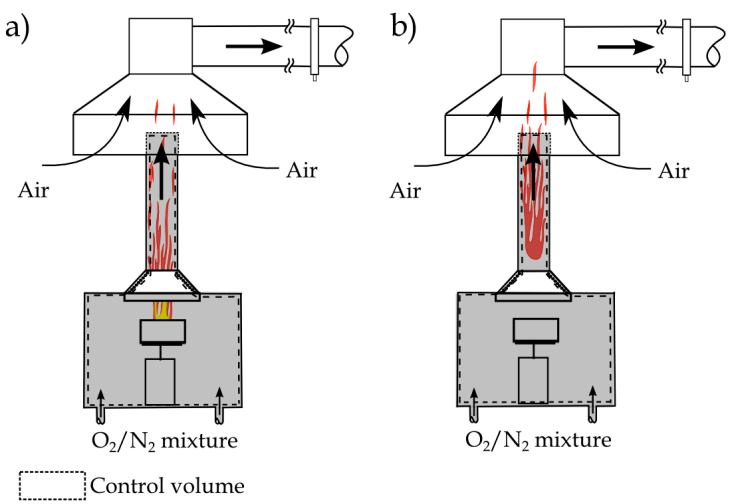

Fig. 5: Transition of combustion behaviour during the experiments. a) Diffusion flame at the PMMA surface when $X_{O_{2}}^{B}>10$ vol\%. b) Premixed flame occurring in the chimney when $X_{o_{2}}^{B}=10 \mathrm{vol} \%$

Considering experimental uncertainties, the results in Fig. 4 indicate that the gas phase behaviour is affected by the $\mathrm{O}_{2}$ depletion. Experimental observations revealed that at $12.5 \mathrm{vol} \%$ of oxygen in the enclosure atmosphere and above, the flaming combustion occurs at the surface of the PMMA sample as shown in Fig. 5.a, and that he combustion efficiency depends on the oxygen concentration in the enclosure. The HRR (Fig. 4.a) and generation rate of $\mathrm{CO}_{2}$ (Fig. 4.b) are the highest at $21^{\circ} \mathrm{vol} \%$ and decrease in a 
depleted oxygen environment. For oxygen concentrations lower than $12.5 \mathrm{vol} \%$, a transition of the combustion behaviour can be observed from a diffusion flame at the sample surface (Fig. 5.a) to a premixed flame within the chimney, as shown in Fig. 5.b. At $X_{o 2}^{B}=10 \mathrm{vol} \%$, the mixture of gas and oxidant is close to the lower flammability limit. In order to evaluate the limiting oxygen concentration ( $L O C$, also known as the Minimum Oxygen Concentration, $M O C$ ) below which combustion is not possible, and considering the composition of the fuel in gas phase is actually unknown, it can be assumed that methylmethacrylate $\left(\mathrm{C}_{5} \mathrm{H}_{8} \mathrm{O}_{2}\right)$ is the main volatile resulting from the polymer decomposition [39]. Hence, the ignition occurs when enough methyl-methacrylate $(M M A)$ [40] reaches the $L F L\left(L F L_{M M A} \sim 1.7 \mathrm{vol} \%\right.$ [41]). Furthermore, the combustion reactions of the $M M A$ are complete, even if at $X_{O_{2}}^{B}=10 \mathrm{vol} \%$, there is formation of $\mathrm{CO}$ (see Fig. 4.c).

$$
\mathrm{C}_{5} \mathrm{H}_{8} \mathrm{O}_{2}+6 \mathrm{O}_{2} \rightarrow 5 \mathrm{CO}_{2}+4 \mathrm{H}_{2} \mathrm{O}
$$

Eq. 3 shows, under stoichiometric conditions, that to obtain complete combustion of 1.7 vol\% of MMA $10.2 \mathrm{vol} \%$ of oxygen is required. This value is close to the experimental measurement of XIN [42], who found it to be $10.48 \mathrm{vol} \%$. Experiments show that the concentration of MMA reaches the LFL MMA $\left(\sim 1.7 \mathrm{vol} \%\right.$ ), when the mass flux of gaseous fuel is equal to $17.5 \mathrm{~g} \cdot \mathrm{s}^{-1} \cdot \mathrm{m}^{-2}$ (see Fig. $2 . \mathrm{b}$ at $t=280 \mathrm{~s}$ when ignition occurs). This mass flux is the critical mass flux of gaseous fuel as defined by RASBASH et al. [8], which depends on the irradiance level and oxygen concentration. The ignition occurs above the spark igniter when the oxygen concentration and the mass flux of gases fuel are sufficient. Because of the turbulent mixing conditions, the $L F L$ of thee Air/Fuel/ $\mathrm{N}_{2}$ mixture is achieved in the chimney instead of above the PMMA surface. As the mixture reaches the $L F L$ near the igniter, a turbulent flame propagates upward to the top of the chimney, leading to the formation of a premixed flame. BITEAU et al. [43] assume that this modification in the regime of combustion - from a diffusion flame to a premixed flame - is related to the increase of incoming inert gases, primarily $\mathrm{N}_{2}$. Indeed, following the BITEAU et al. [43] and WhITE [44], the incoming $\mathrm{N}_{2}$ in the reacting atmosphere increases the thermal capacity of the combustion gas mixture, which limits the flame temperature and the combustion. Due to the high $\mathrm{N}_{2}$ concentration, the flame does not propagate back to the PMMA surface and remains confined in the chimney. This premixed flame is too far from the sample to cause significant radiation to the sample surface and to affect the thermal balance at the surface, and thus the decomposition rate (Figs. 2.a-b). These observations explain why the kinetics at 10 vol\% of $\mathrm{O}_{2}$ or lower are similar. At 10 vol\% of $\mathrm{O}_{2}$, the heating of the sample and its decomposition are therefore only due to the radiation of the conical heater, as shown in Fig. 3 . It is interesting to note that, at this oxygen concentration, sustained combustion may occur only with a sufficiently high chimney. MARQUIS et al. [21] have recently determined that combustion conditions depend on the CACC design. It was shown that in the case of CACC without chimney, no sustained ignition of the PMMA is observed. Indeed, flames are blown off by the ambient air when gases emerge from the combustion enclosure, and the mixture becomes too diluted to achieve the $L F L$.

When $X_{O_{2}}^{B}<10 \mathrm{vol} \%$, the quantity of available oxidant seems to be lower than the $L O C$ and flaming cannot be sustained. Consequently, the HRR and $\mathrm{CO}_{2}$ generation rate are significantly reduced.

Concerning the $C O$ production rate (see Fig. 4.c), the behaviour is different and depends on the combustion conditions. At 21 and $15 \mathrm{vol} \%$ of $\mathrm{O}_{2}$, experiments show the presence of $C O$ during the $\gamma$ step $\left(\gamma_{21}\right.$ and $\gamma_{15}$ steps). During this step, the MLR reaches its maximum [see Fig. 2]. Measurements suggest that the mixture during this period is below stoichiometry. According to PITTS [45], when the available amounts of $\mathrm{O}_{2}$ in the enclosure and inside the material are too low to reach stoichiometry, oxidation reactions of hydrocarbons species to $C O$ are promoted. Therefore, according to PITTS [45] and GOTTUK et al. [46], not enough free radicals (i.e. $\mathrm{OH}^{\bullet}$ and $\mathrm{HO}_{2}{ }^{\bullet}$ ) are available in the enclosure during the $\gamma$ step - compared to the significant amount of unburnt hydrocarbons - in order to oxidize $\mathrm{CO}$ to $\mathrm{CO}_{2}[45,46]$. They suggest, furthermore, that the free radicals react faster with the fuel gases than with $C O$. This gas production leads to the vitiation of the enclosure atmosphere. It is of interest to emphasize that under well-ventilated conditions (at $21 \mathrm{vol} \%$ of $\mathrm{O}_{2}$ ), no peaks of this magnitude were observed by LUCHE et al. [15] using the standard cone calorimeter. Therefore, this behaviour seems to be related to the use of the combustion enclosure and depends on the available amount of $\mathrm{O}_{2}$ entering and thus on the airflow rate.

At $12.5 \mathrm{vol} \%$ and $10 \mathrm{vol} \%$ of $\mathrm{O}_{2}$, production of $\mathrm{CO}$ is recorded earlier (during the $\alpha$ and $\gamma$ stages). Under fuel rich conditions, the oxidation reactions of the gaseous products to $C O$ seem to be promoted rather than the generation of $\mathrm{CO}_{2}$. Indeed, Fig. 4.c shows a linear evolution of the $\mathrm{CO}$ production during the 
aforementioned steps. The measurements suggest that the available amount of $\mathrm{O}_{2}$ entering into the enclosure is insufficient to oxidize $\mathrm{CO}$ to $\mathrm{CO}_{2}$, leading to incomplete combustion and vitiation of the atmosphere. Below 10 vol\% of $\mathrm{O}_{2}$, the air/fuel mixture is unreactive. $\mathrm{CO}$ production drops significantly and follows an asymptotic behaviour. This result suggests that its production rate is not influenced by the composition of the reacting atmosphere.

\section{Effects of inlet airflow rate in the oxygen controlled enclosure}

In this section, the results are discussed of experiments that were performed at several volume flow rates at the inlet of the combustion enclosure. Four series of tests were conducted to explore ventilation effects. The

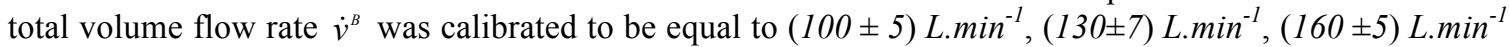

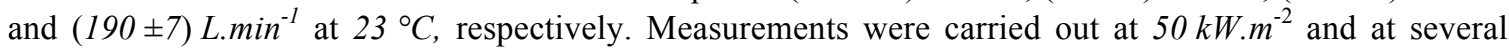
oxygen concentrations $X_{O_{2}}^{B}(10 \mathrm{vol} \%, 15 \mathrm{vol} \%$ and $21 \mathrm{vol} \%)$. Figs. $6 \& 7$ present the effect of the inlet volume airflow rate in the enclosure on the $\mathrm{CO} / \mathrm{CO}_{2}$ ratio and the HRR, respectively. Uncertainties were estimated respectively at $12 \%$ for the $\mathrm{HRR}$ and $7 \%$ for the ratio $\mathrm{CO} / \mathrm{CO}_{2}$.
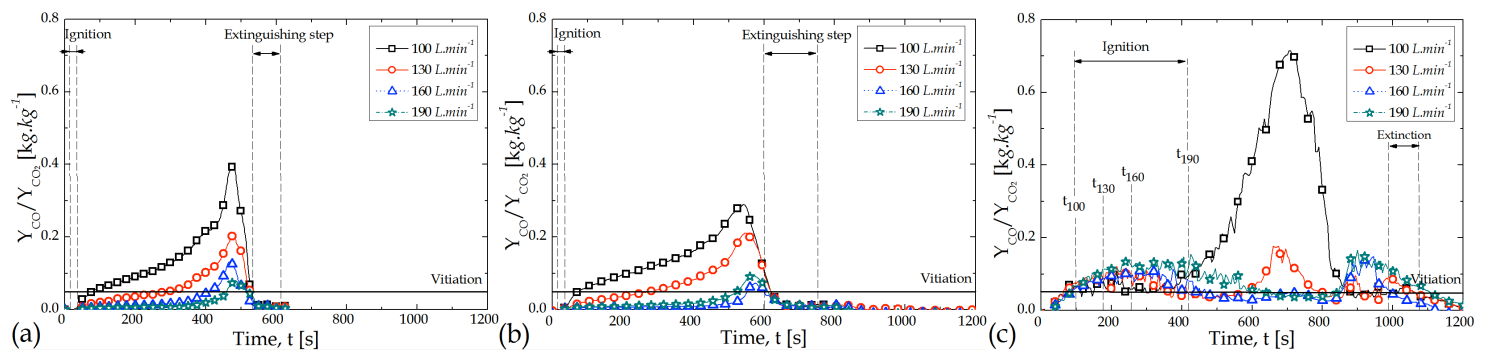

Fig. 6. Effect of inlet volume flow rate in the combustion enclosure on the $\mathrm{CO} / \mathrm{CO}_{2}$ ratio at different oxygen concentrations: (a) $X_{o_{2}}^{B}=21 \mathrm{vol} \%$, (b) $X_{o_{2}}^{B}=15 \mathrm{vol} \%$ and (c) $X_{O_{2}}^{B}=10 \mathrm{vol} \%$.
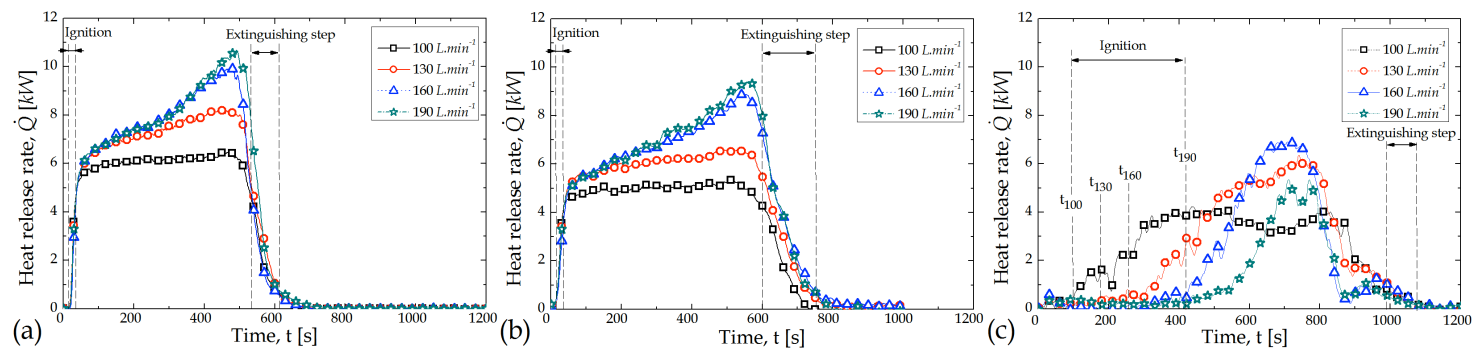

Fig. 7. Effect of inlet volume airflow rate in the combustion enclosure on the average HRR per unit area at several oxygen concentrations: (a) $X_{o_{2}}^{B}=21 \mathrm{vol} \%$, (b) $X_{o_{2}}^{B}=15 \mathrm{vol} \%$ and (c) $X_{o_{2}}^{B}=10 \mathrm{vol} \%$.

From 21 vol\% down to $15 \mathrm{vol} \%$ of $\mathrm{O}_{2}$, Figs. 6.a-6.b \& 7.a-7.b indicate that the $\mathrm{CO} / \mathrm{CO}_{2}$ ratio and $\mathrm{HRR}$ change radically. Significant effects on the kinetics can be observed when the airflow is lowered. When reducing the inlet volume airflow rate, the available amount of oxygen entering in the control volume for the combustion reaction is limited. As a result, the combustion regime in the gas phase is affected and the quantity of heat released is reduced (see Figs. 7.a-7.b) whereas the $\mathrm{CO} / \mathrm{CO}_{2}$ ratio is increased (see Figs. 6.a6.b). ISO 19706 [47] indicates that combustion conditions may be considered as incomplete and the atmosphere may be assumed as "vitiated" when the $\mathrm{CO} / \mathrm{CO}_{2}$ ratio is higher than 0.05 (Fig. 6). At 100

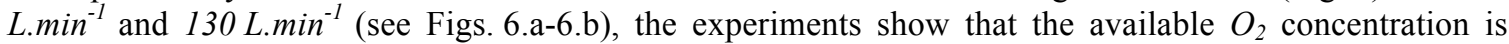
insufficient to obtain combustion under stoichiometric conditions, leading to air vitiation in the enclosure. That skews the accuracy of the measurements because the amount of $\mathrm{O}_{2}$ in the enclosure is different from that in the incoming mixture, modifying the combustion of gases. These results are consistent with the

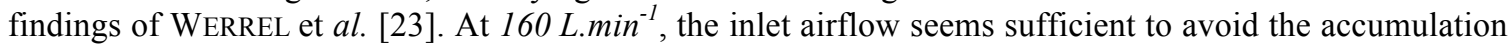
of fuel gases within the enclosure $\left(\mathrm{CO} / \mathrm{CO}_{2}<0.05\right)$ and reduce the vitiation of the atmosphere. At this airflow, a peak of $\mathrm{CO} / \mathrm{CO}_{2}$ can be observed around $t=580 \mathrm{~s}$, as a result of the flame extinction. Over $160 \mathrm{~L}_{\mathrm{min}} \mathrm{min}^{-1}$, emissions follow an asymptotic behaviour, and the $\mathrm{CO} / \mathrm{CO}_{2}$ ratio remains unchanged during the test. The experiments indicate that there is a threshold value of airflow that drives the fire behaviour 
( $\mathrm{HRR}$ and $\mathrm{CO} / \mathrm{CO}_{2}$ ratio). According to these results, the inlet airflow in the enclosure must be at least

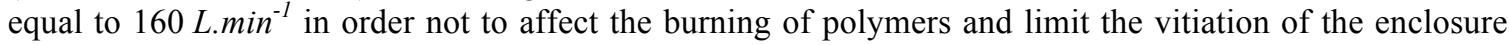
atmosphere.

At $X_{o_{2}}^{B}=10 \mathrm{vol} \%$ (see Fig. 6.c), the $\mathrm{CO} / \mathrm{CO}_{2}$ ratio is similar to the experiments at 15 and $21 \mathrm{vol} \%$ of $\mathrm{O}_{2}$. However, a significant increase is found when the inlet airflow is reduced. The HRR is also affected (see Fig. 7.c). In contrast with the results at $X_{o_{2}}^{B}=15$ and $21 \mathrm{vol} \%$ where only the magnitude of the $H R R$ is affected, at $X_{O_{2}}^{B}=10 \mathrm{vol} \%$, the duration of the combustion is also impacted. Furthermore, Fig. 7.c shows that an increased inlet airflow affects the dilution and the ignition time, i.e., the time to achieve the LFL close to pilot igniter. Indeed, the ignition time is delayed when the airflow increases, whereas the extinction happens almost at the same time regardless of the inlet flow. These results confirm the observations made by WERREL et al [23]. When the inlet airflow rate in the enclosure increases, the characteristic mixing time $\tau_{\mathrm{m}}$ during which the active molecules of $\mathrm{O}_{2}$ and fuel coexist and may react, decreases. As the mixing time becomes shorter than the characteristic chemical time $\tau_{\text {ch }}$ (i.e the necessary time for the reaction chemistry to occur), no sustained flaming may subsist. The flame is also blown by aerodynamic quenching at high airflow $\left(190 \mathrm{~L}_{\mathrm{min}} \mathrm{min}^{-1}\right.$. The classical extinction theory is based on the concept of a critical Damköhler number $\left(\mathrm{D}_{\mathrm{a}}=\tau_{\mathrm{m}} / \tau_{\mathrm{ch}}\right)$ and assumes that $\mathrm{D}_{\mathrm{a}}<<1$ [48]. Hence, at $X_{o 2}^{B}=10 \mathrm{vol} \%$, as the mixture Air $/ \mathrm{Fuel} / \mathrm{N}_{2}$ is close to the $L F L$, increasing the airflow tends to delay (or possibly prevent) the ignition of the mixture and promotes its extinction. For example, at $190 \mathrm{~L}^{\mathrm{min}} \mathrm{min}^{-1}$ (see Fig. 8.c), the results show that the ignition time

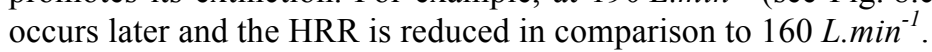

The increase of airflow promotes the dilution of the mixture and the flame dynamics. However, it seems also to intensify the post-oxidation phenomenon. As mentioned previously, because of the open design of the CACC, chemical oxidation of smoke with the surrounding ambient air of the laboratory can occur between the combustion enclosure and the sampling point in the exhaust duct for HRR and gas measurements. In the case of the PMMA, which is a material with a high calorific potential, the flames are not contained within the chimney and part of the fuel vapours burn outside, consuming oxygen of the surrounding air of the laboratory. This phenomenon has a significant adverse effect on the accuracy of the HRR and leads to misleading results. Whether this problem exists can be determined by analysing the flow rate of $\mathrm{CO}, \mathrm{CO}_{2}$ and $\mathrm{O}_{2}$ both at the top of the chimney and at the downstream exhaust sampling point (where all measurements for HRR calculations are usually performed). The calculation of HRR could then be performed by another formula developed by JANSSENS and adapted to the CACC [31], based on the inlet airflow rate and oxygen consumption rather than on the exhaust airflow rate. However, this approach should be applied only to materials with a low calorific potential so that the flame does not extend beyond the top of the chimney and therefore skews the measurements. Hence, it is not possible to use this approach for PMMA.

Fig. 8 shows the effects of the inlet volume airflow rate in the combustion enclosure on the MLR at several oxygen concentrations. Uncertainties were estimated at $7 \%$
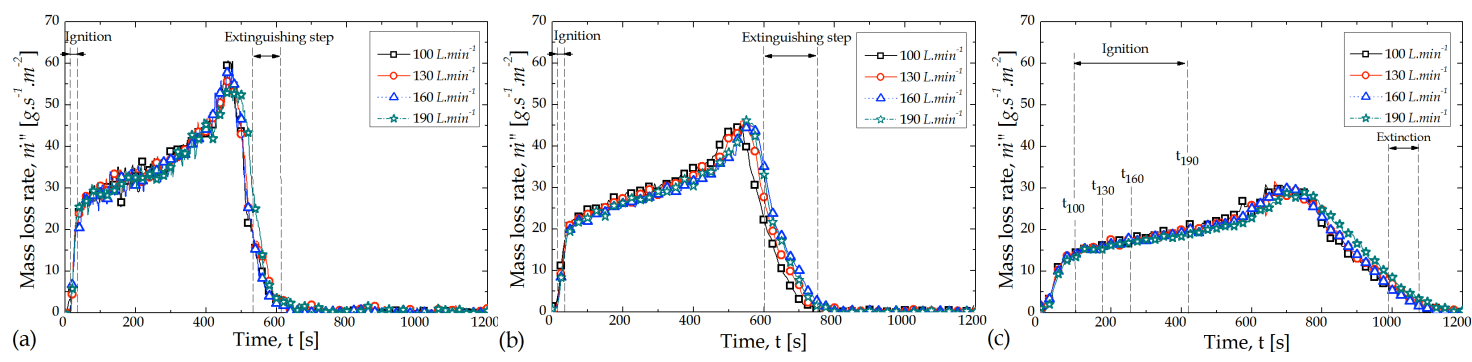

Fig. 8. Effect of inlet volume flow rate in the combustion enclosure on the average MLR at several oxygen concentrations: (a) $X_{o_{2}}^{B}=21 \mathrm{vol} \%$, (b) $X_{o 2}^{B}=15 \mathrm{vol} \%$, and (c) $X_{o_{2}}^{B}=10 \mathrm{vol} \%$.

In contrast with the gas phase (Figs. $6 \& 7$ ), the rate of inlet airflow has no real impact on the reactivity of the condensed phase. For each of the tested airflows, the experiment reveals that mass flux of decomposition exhibits similar dynamics.

On the one hand, this result suggests that the airflow rate injected from the two-gas inlet ports at the bottom of the enclosure (Fig. 1) does not have a cooling effect on the condensed phase when the sample is 
positioned in horizontal orientation. Increasing the airflow rate does not change the decomposition rate. In contrast, it affects only the fuel gases dynamics and modifies the position where the Air/Fuel $/ \mathrm{N}_{2}$ mixture reaches stoichiometry. The behaviour in the solid phase might be different for samples in the vertical orientation or if the Air $/ \mathrm{N}_{2}$ mixture is introduced on the side of the enclosure, because the convective heat transfer at the sample surface would certainly be thus modified.

On the other hand, experiments show that the heat released by the flame does not seem to have any effect on the thermal balance of the sample. Fig. 7 shows that the HRR depends on the inlet airflow in the chamber, whereas the MLR remains constant. As mentioned previously, at $10 \mathrm{vol} \%$ of $\mathrm{O}_{2}$, the premixed flame is too far from the sample and the radiant heat flux from the flame to the surface is too low to affect the thermal decomposition of the sample. Moreover, at $15 \mathrm{vol} \%$ and $21 \mathrm{vol} \%$ of $\mathrm{O}_{2}$ (i.e. oxygen concentrations for which a diffusion flame can be observed) the thermal feedback of the flame to the sample seems to be constant for a given concentration regardless the inlet airflow.

\section{CONCLUSIONS}

Recent work in a controlled oxygen environment raises the question of interpretation and accuracy of the test results. In the present work, an open controlled atmosphere cone calorimeter with a $0.6 \mathrm{~m}$ high chimney was used to study the effect of the controlled ventilation conditions on the burning behaviour of black PMMA.

In condensed phase, the conclusions are consistent with the findings of KASHIWAGI $[16,17]$. If a diffusion flame is present, the flame temperature and the combustion efficiency substantially increase the radiative feedback received at the PMMA surface, resulting in a higher MLR. The combustion reactions deprive the region above the PMMA of the oxygen, limiting the possibility of oxidation reactions of the PMMA condensed phase. All oxidative reactions at the surface cease. The reduction of the flame temperature below a specific threshold leads to its extinction. In the absence of a flame, the oxidation reaction of PMMA becomes possible only when the mass flux of the gaseous decomposition products does not prevent the diffusion of surrounding oxygen. In contrast to experiments performed by KASHIWAGI at a low irradiance level $\left(17 \mathrm{~kW} \cdot \mathrm{m}^{-2}\right)$, the mass flux of decomposition gasses released at $50 \mathrm{~kW} \cdot \mathrm{m}^{-2}$ is too high to allow surface oxidation of the PMMA.

The reduction of the oxygen concentration in the enclosure mainly affects the reactions in the gas phase and results in changes of the burning behaviour. Thus, below 12.5 vol\% of $\mathrm{O}_{2}$, a transition occurs from a diffusion flame at the sample surface to a premixed flame inside the chimney. As the mixture of gas and oxidant is close to the lean flammability limit, and because of the turbulent mixing conditions, the $L F L$ of the Air/Fuel/ $\mathrm{N}_{2}$ mixture is achieved in the chimney, leading to premixed combustion. However, the flame in this case is too far from the PMMA sample to heat it directly by radiation and to affect its decomposition rate. It is important to highlight that this behaviour does not occur in absence of chimney and therefore depends upon CACC design.

The inlet airflow rate is the fundamental parameter that controls the burning of polymeric material in an enclosure. Analyses of results from tests performed on black PMMA have revealed that the choice and the control of the inlet airflow is a determining factor to study a material in a controlled oxygen environment because it defines the quantity of oxygen available and therefore influences the burning process. Furthermore, in the condensed phase, the experiments show that the airflow does not have a cooling effect on the material burning behaviour in the CACC configuration (i.e. with a Air/ $\mathrm{N}_{2}$ introduced at the bottom of the enclosure). Even if the airflow affects the combustion phase (HRR and gas production) and the mixing conditions, the heat released by the flame remains constant regardless of the inlet airflow. Therefore, the MLR of the sample for a given oxygen concentration is not affected (see Figs. $7 \& 8$ ). In the gas phase, low values of airflow in the enclosure generate vitiation, limiting the possible chemical reaction between $\mathrm{O}_{2}$ and the gaseous fuel, and leading to inaccurate estimates of the available oxygen in the enclosure. This could be misleading when trying to understand the phenomena or simply analyzing the results. In contrast, a too high value of airflow will affect the dilution of the mixing, local concentration of fuel/oxidant in the gas stream and blow off the flame. These results are consistent with the findings of WERREL et al. [23]. Furthermore, the HRR is directly dependent of the available amount of oxygen, which is induced by the inlet airflow. An increasing airflow therefore amplifies the dilution of the mixture and the flame dynamics but also seems to affect the intensity of the post-oxidation phenomenon. 
The experimental results suggest, at a $50 \mathrm{~kW} \cdot \mathrm{m}^{-2}$ irradiance level, that the inlet airflow rate in the enclosure must be close to $160{\mathrm{~L} . \mathrm{min}^{-1}}^{-}$in order not to vitiate the atmosphere during tests and affect the burning rate. Additional work and more detailed investigations should be performed in the future in order to: (1) evaluate the accuracy of the HRR and gas concentration measurements in the actual open CACC design; (2) quantify the contribution of the post oxidation reactions outside the combustion enclosure; (3) assure that the obtained results can be observed for different polymeric materials; (4) define the best CACC design to study the burning behaviour in an oxygen vitiated environment.

It can be concluded that the definition of an experimental protocol is necessary to ensure harmonization of the analysis and avoid biased results. In the future, standardization could lead to the development of a single method and a unique design of the CACC, thus allowing consistent observations of burning behaviour. Presently, the lack of international harmonization does not allow for a clear and direct comparison of results between actual studies led in different laboratories (reproducibility). Such a harmonization is currently under preliminary discussion within the international committee ISO TC92.

\section{ACKNOWLEDGEMENTS}

The authors acknowledge Damien Lesenechal, Frederic De Lagos, Franck Didieux and Fabien Hermouet. Thanks to Dr. M. Janssens for his pertinent comments.

\section{REFERENCES}

[1] Babrauskas, V., (1984) Development of the cone calorimeter - A bench-scale heat release rate apparatus based on oxygen consumption, Fire and Materials 8: 81-95, http://dx.doi.org/10.1002/fam.810080206

[2] ISO 5660-1, (2002) Reaction-to-fire tests - Heat release, smoke production and mass loss rate Part 1: heat release rate (cone calorimeter method), http://www.iso.org.

[3] Mulholland, G., Twilley, W., Babrauskas V., Janssens, M., and Yusa S., The effect of oxygen concentration on $\mathrm{CO}$ and smoke produced by flames, Fire safety science -- Proceeding of the 3rd Int. Symp., IAFSS, 1991, pp.585-594

[4] Babrauskas, V. Twilley, W.H., Janssens, M., and Yusa, S., (1992) A cone calorimeter for controlled atmosphere studies, Fire and materials 16: 37-43 http://dx.doi.org/10.1002/fam.810160106

[5] ASTM E 2058-13, (2013) Standard test method for measurement of synthetic polymer material flammability using a fire propagation apparatus (FPA). http://dx.doi.org/10.1520/E2058-13

[6] McAllister, S., Fernandez-Pello, C., Urban, D., and Ruff, G., (2010) The combined effect of pressure and oxygen concentration on piloted ignition of a solid combustible, Combustion and flame, 157: 1753-1759, http://dx.doi.org/10.1016/j.combustflame.2010.02.022

[7] Fereres, S., Lautenberger, C., Fernandez-Pello, C., Urban, D., and Ruff, G., (2011) Mass flux at ignition in reduced pressure environments, Combustion and flame 158: 1301-1306, http://dx.doi.org/10.1016/j.combustflame.2010.11.013

[8] Rasbash, D.J., Drysdale D.D., and Deepak, D., (1986) Critical heat and mass transfer at pilot ignition and extinction of a material, Fire safety journal 10: 1-10, http://dx.doi.org/10.1016/03797112(86)90026-3

[9] Cordova, J.L., Walther, D.C., Torero, J.L., and Fernandez-Pello, A.C., (2001) Oxidizer flow effects on the flammability of solid combustibles, Combustion science and technology 164: 253278, http://dx.doi.org/10.1080/00102200108952172

[10] Tewarson, A., and Ogden, S.D., (1992) Fire behaviour of polymethylmethacrylate, Combustion and flame 89: 237-259, http://dx.doi.org/10.1016/0010-2180(92)90013-F

[11] Cordova, J.L., and Fernandez-Pello, C., (2000) Convection effects on the endothermic gasification and piloted ignition of a radiatively heated combustible solid, Combustion science and technology 156: 271-289, http://dx.doi.org/10.1080/00102200008947306 
[12] Tsai, K-C., (2009) Orientation effect on cone calorimeter test results to assess fire hazard of $\begin{array}{lllll}\text { materials, Journal of } & \text { 763-772, }\end{array}$ http://dx.doi.org/10.1016/j.jhazmat.2009.07.061

[13] Rich, D., Lautenberger, C., Torero, J.L., Quintiere, J.G., and Fernandez-Pello, C., (2007) Mass flux of combustible solids at piloted ignition, Proceedings of the Symposium (international) on Combustion 31: 2653-2660, http://dx.doi.org/10.1016/j.proci.2006.08.055

[14] Beaulieu, P. A., Flammability Characteristics at Heat Flux Levels up to 200 kW.m-2 and the Effect of Oxygen on Flame Heat Flux, PhD Thesis, Worcester Polytechnic Institute, 2005.

[15] Luche, J., Rogaume, T., Richard, F., and Guillaume, E, (2011) Characterization of thermal properties and analysis of combustion behaviour of PMMA in a cone calorimeter, Fire safety journal, 46 pp. 451-461. http://dx.doi.org/10.1016/j.firesaf.2011.07.005

[16] Kashiwagi, T., (1994) Polymer combustion and flammability - Role of the condensed phase, Proceedings of the Symposium (international) on Combustion 25: 1423-1437, http://dx.doi.org/10.1016/S0082-0784(06)80786-1

[17] Kashiwagi, T., and Ohlemiller, T.J., (1982) A study of oxygen effects on non flaming transient gasification of PMMA and PE during thermal irradiation, Proceedings of the Symposium (international) on Combustion 19 815-823, http://dx.doi.org/10.1016/S0082-0784(82)80257-9

[18] Hirata, T., Kashiwagi, T., and Brown, J.E., (1985) Thermal and oxidative degradation of Poly(methyl methacrylate): Weight loss, Macromolecules 18: 1410-1418, http://dx.doi.org/10.1021/ma00149a010

[19] Tewarson, A., Jiang, F.H., and Morikawa, T., (1993) Ventilation controlled combustion of polymers, Combustion and flame 95: 151-169, http://dx.doi.org/10.1016/0010-2180(93)90058-B

[20] Tewarson, A., Lee, J.L., and Pion, R.F., (1980) The Influence of Oxygen Concentration on Fuel Parameters for Fire Modeling, Proceedings of the Symposium (international) on Combustion 18(1): 563-570. http://dx.doi.org/10.1016/S0082-0784(81)80061-6

[21] Marquis, D.M., Guillaume, E. and Lesenechal, D. (2013) Accuracy (trueness and precision) of cone calorimeter test with and without a vitiated air enclosure. Journal of Procedia Engineering 9th Asia-Oceania Symposium on Fire Science and Technology 62;103-119 http://dx.doi.org/10.1016/j.proeng.2013.08.048

[22] Werrel, M., Deubel, J.H., Krüger, S., Hofmann, A., and Krause, U., (2013) The calculation of the heat release rate by oxygen consumption in a controlled-atmosphere cone calorimeter. Fire and Materials. http://dx.doi.org/10.1002/fam.2175 (Online)

[23] Werrel M. Deubel, J.H., Krüger S., Hofmann A., Antonatus E., Krause U. and Deuerler, F., Use and benefit of a controlled atmosphere cone calorimeter, Proceeding in the 13th International conference Fire and Material, 2013, pp. 273-285.

[24] Bal N., Uncertainty and complexity in pyrolysis modeling, PhD Thesis, Edinburgh university, 2012

[25] ISO 291, (2005) Plastics — standard atmospheres for conditioning and testing, http://www.iso.org

[26] ISO 1183-1, (2004) Plastics - methods for determining the density of non-cellular plastics—part 1: immersion method, liquid pyknometer method and titration method, http://www.iso.org

[27] Mikkola, E., Effects of oxygen concentration on cone calorimeter results, Proceedings of the Sixth International Fire Conference (INTERFLAM), 1993, pp 49-56

[28] Hietaniemi, J., Kallonen, R., and Mikkola E., (1999) Burning characteristics of selected substances: production of heat, smoke and chemical species. Fire and Materials 23:171-185 http://dx.doi.org/10.1002/(SICI)1099-1018(199907/08)

[29] Hugget, C., (1980) Estimation of rate of heat release by means of oxygen consumption measurements. Fire and Materials 12(2): 61-65. http://dx.doi.org/10.1002/fam.810040202 
[30] Janssens, M., (1991) Measuring rate of heat release by oxygen consumption. Fire Technology 27: 234-249. http://dx.doi.org/10.1007/BF01038449

[31] Janssens, M., and Parker, W.J., "Oxygen consumption calorimeter", Heat release in fires, Babrauskas, V., And Grayson, S.J., editors, London, Edt Elsevier, 1992. pp. 31-59

[32] Thornton, W., (1917) The Relation of Oxygen to the Heat of Combustion of Organic Compounds. Philosophical Magazine and Journal of Science 33: 196-203, http://dx.doi.org/10.1080/14786440208635627

[33] Tewarson, A. "Generation of Heat and Gaseous, Liquid and Solid Products in Fire," The SFPE handbook of Fire Protection Engineering. (4th edt), NFPA, 2008, pp. 3.109-3.194

[34] ISO/TS 5660-3, (2012) Reaction-to-fire tests -- Heat release, smoke production and mass loss rate -- Part 3: Guidance on measurement, http://www.iso.org

[35] Girods, P., Bal N., Biteau H., Rein G., and Torero J.L., "Comparison of pyrolysis behaviour results between the cone calorimeter and the fire propagation apparatus heat sources", Fire safety science--Proceeding of 10th International Symposium on Fire Safety Science, 2011

[36] Försth, M., and Roos, A., (2010) Absorptivity and its dependence on heat source temperature and degree of thermal breakdown, Fire and Materials 35(5): 285-301. http://dx.doi.org/10.1002/fam.1053

[37] Torero, J.L., "Flaming ignition of solid fuels", The SFPE handbook of Fire Protection Engineering. (4th edt), NFPA, 2008, pp. 2.260-2.278

[38] Joint Committee for Guides in metrology (JCGM) 1995. Evaluation of measurement data - Guide to the expression of Uncertainty in Measurement

[39] Kashiwagi, T., and Inaba, A., (1989) Behavior of primary radicals during thermal degradation of poly(methyl methacrylate). Polymer Degradation and Stability 26: 161-184,

[40] Bonnard, N., Brondeau, M.T., Jargot, D., Pillière, F., Schneider, O., and Serre, P., Méthacrylate de méthyle, Fiche toxicologique FT62, INRS, 2008.

[41] Bodurtha, F.T. Industrial explosion prevention and protection, Mc Grow Hill New York 1980.

[42] Xin, Y. and Khan, M.M., (2007) Flammability of combustible materials in reduced oxygen environment, Fire safety journal 42: 536-547, http://dx.doi.org/10.1013/j.firesaf.2007.04.00

[43] Biteau, H., Fuentes, A., Marlais, G., and Torero, J.L., (2010) The influence of oxygen concentration on the combustion of a fuel/oxidizer mixture. Experimental Thermal and Fluid Science 34: 282-289, http://dx.doi.org/10.1016/j.expthermflusci.2009.10.025

[44] White, A.G. (1925) Limits for the propagation of flame in inflammable gas-air mixtures, part III. The effect of temperatures on the limits, Journal of the Chemical Society 127: 672-684.

[45] Pitt, W., (1994) Application of thermodynamics and detailed chemical modelling to understanding combustion product generation in enclosure fire, Fire safety journal 23: 271-303, http://dx.doi.org/10.1177/0734904110363106

[46] Gottuk, D.T., Roby, RJ., and Beyler, C.L., (1995) The role of temperature on carbon monoxide production in compartment fire, Fire safety journal 24: 315-331, http://dx.doi.org/10.1177/104239159200400402

[47] ISO 19706, (2011) Guidelines for assessing the fire threat to people, http://www.iso.org

[48] Williams, F.A., (2000) Progress in knowledge of flamelet structure and extinction, Progress in Energy and Combustion Science 26: 657-682, http://dx.doi.org/10.1016/S0360-1285(00)00012-5 